\section{COVID-19 and school food: The impact of the early stages of the coronavirus pandemic on student nutrition programs in Ontario}

\author{
Indra Noyes a*
}

University of Waterloo

Nicola Lyle ${ }^{b}$

Peterborough Child and Family Centres
SPECIAL ISSUE COSPONSORED BY INFAS: THE IMPACT OF COVID-19 ON FOOD SYSTEMS

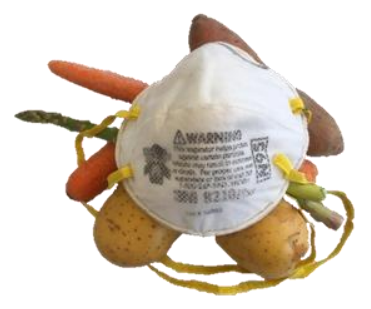

Inter-institutional

Network for

Food and Agricultural Sustainability

Submitted September 29, 2020 / Revised January 18 and February 26, 2021 / Accepted March 3, 2021 /

Published online April 6, 2021

Citation: Noyes, I., \& Lyle, N. (2021). COVID-19 and school food: The impact of the early stages of the coronavirus pandemic on student nutrition programs in Ontario. Journal of Agriculture, Food Systems, and Community Development, 10(2), 197-210. https://doi.org/10.5304/jafscd.2021.102.049

Copyright (C) 2021 by the Authors. Published by the Lyson Center for Civic Agriculture and Food Systems. Open access under CC-BY license.

\begin{abstract}
This paper is an exploration of the impact of the early stages of the COVID-19 pandemic on emergency food supply to school-aged children in Ontario, Canada. Using surveys in the framework of a bounded qualitative case study, we investigate how Student Nutrition Program (SNP) support staff have responded to the changed circumstances of the pandemic. Results indicate that program support staff were able to shift the SNP's focus from universal access in-school nutrition programs
\end{abstract}

a* Corresponding author: Indra Noyes, Ph.D. Candidate, Balsillie School of International Affairs, University of Waterloo; 67 Erb St W, Waterloo, ON, N2L 6C2 Canada; inoyes@uwaterloo.ca

\footnotetext{
b Nicola Lyle, Director of Administrative Services, Peterborough Child and Family Centres; 201 Antrim Street, Peterborough, ON, K9H3G5, Canada.
}

to targeted food security initiatives for families. This shift was possible due to the complex web of relationships within which SNPs in Ontario operate. Additional data and findings are discussed in the article, relating to the prepandemic operation of SNPs, how programs have been affected, and the concerns of SNP support staff about future issues as the programs restart in the new school year under pandemic conditions.

\section{Keywords}

School Nutrition Programs, Student Nutrition

\section{Disclosures}

Indra Noyes is a former employee of the Peterborough Child and Family Centres, having worked closely with many of the research participants regularly in her role as student nutrition support staff. Nicola Lyle is currently the regional manager of student nutrition programs in Central East Ontario through Peterborough Child and Family Centres. 
Programs, COVID-19, Pandemic, Qualitative Research, Food Security

\section{Introduction}

\section{Early Impact of COVID-19}

As the COVID-19 pandemic wreaks havoc on contemporary food systems, it reveals inherent flaws and weaknesses of these systems (Altieri \& Nicholls, 2020; Clapp, 2020; Clapp \& Moseley, 2020). The initial global lockdown to slow the spread of COVID-19 affected food systems and disrupted the complex, global food supply networks. Noteworthy examples of this disruption include large-scale logistic barriers, resulting in the dumping of fluid milk (Yaffe-Bellany \& Corkery, 2020a) and mass slaughter of livestock (YaffeBellany \& Corkery, 2020b). Furthermore, the pandemic highlights the essential role of migrant farm labor (Hennebry, Caxaj, McLaughlin, \& Mayell, 2020) and food processing facilities (Hailu, 2020) in contemporary food systems. Beyond such immediate shocks to the food system, it is estimated that the number of people living in acute hunger globally will double to 265 million people as a result of the pandemic, according to the United Nations' World Food Program (Anthem, 2020). According to the United Nations' Food and Agriculture Organization (FAO), the growing food insecurity and hunger impact of COVID-19 is particularly prevalent in less wealthy countries and amongst vulnerable populations (FAO, 2020).

This global trend is also reflected in the Canadian context, where the shock of the COVID-19 pandemic has had particularly deep reverberations through the emergency food supply system (Deaton \& Deaton, 2020). With the beginning of the lockdown in March 2020, and in subsequent months, food banks saw a surge in demand (Food Banks Canada, 2020). City of Toronto food banks saw an increase of $25 \%$ in the number of food bank visits per week, alongside a $200 \%$ increase in new clients (Daily Bread Food Bank, 2020). This increase in food bank use was also reflective of an increase in child hunger in the city of Toronto. The Daily Bread Food Bank noted an increase from 4\% to $8 \%$ of children (of families accessing the food bank) experiencing hunger two times a week or more (Daily Bread Food Bank, 2020). It is estimated that children made up $33 \%$ of food bank users in Ontario before the beginning of the pandemic (King \& Quan, 2018). As the pandemic continues, and the economic impacts grow, so will the number of food-insecure households and children (Food Banks Canada, 2020; Paslakis, Dimitropoulus, \& Katzmena, 2021).

\section{Ontario Student Nutrition Programs}

Before the start of the pandemic, children in Ontario living in food-insecure households were able to access emergency food supplies through two avenues: food banks and schools. Schools function as an essential infrastructure in emergency food supply to children by way of operating school food programs (Ralston, Treen, Coleman-Jensen, \& Guthrie, 2017). In Ontario, these school food programs are called Student Nutrition Programs (SNPs). The mandate of SNPs is to serve meals and snacks in a nonstigmatizing environment, creating regular and reliable access to healthy food for children (SNP Guidelines, 2016). A summary of SNP operational structure can be found in Table 1.

These nutrition programs were established as grassroots community initiatives, which accounts for the multitude of stakeholders, as they have evolved substantially over the years.

The pandemic and its impacts are continually evolving, as is our understanding of how COVID19 containment efforts are changing the world. With the sudden closure of all schools in Ontario in March 2020, SNPs lost their venue of operation. In this paper, we examine the impact of the early stages of the COVID-19 pandemic on food supply to schoolchildren in Ontario. Focusing on the first months of the pandemic (March 2020 to August 2020), we surveyed Student Nutrition Ontario (SNO) staff in order to investigate how the pandemic has impacted food supply to Ontario SNPs.

\section{Methods}

This article presents the findings of a qualitative research case study, designed as a single instrumental case study. The survey included six questions focused on understanding the major concerns of staff before the pandemic, how the pandemic impacted programs, how staff responded, and what concerns 


\section{Table 1. Student Nutrition Programs (SNPs) in Ontario}

\begin{tabular}{ll}
\hline Funding & Student Nutrition Programs operate with core support from three levels of the public sector: the \\
& Ontario Government, regional Public Health units, and local schools and school boards (De Wit, \\
& 2012). The programs receive funding (and report to) the Ontario Ministry of Children, Community and \\
Social Services (OMCCSS) and are hosted in the physical jurisdiction of the Ministry of Education. & Additional funding is secured and stewarded through the provincial Student Nutrition Ontario \\
& network and on the community level (SNO, n.d.). Governmental funding is "seed funding" in that it is \\
& a small portion of full operational cost that is provided reliably. \\
\hline Operational Model & SNPs are well-established community initiatives that exist in the majority of public schools \\
& throughout the province (SNO, n.d.). SNPs rely extensively on in-kind support from school staff, \\
& Public Health Units, and community volunteers. The programs face systematic operational barriers \\
& associated with the high cost of healthy food, heavy reliance on volunteerism, and school-level \\
& stigma (Vine, 2014a) \\
\hline GNPs are supported and administered through 14 lead agencies, which are community organizations \\
mandated to deliver SNPs in their region by acting as flow-through organizations for ministry funding \\
(Ministry of Children, Community, and Social Services, 2016). Lead agency staff work in \\
collaboration with community-level organizations, schools, and other stakeholders to flow funding, \\
report to funders, and provide SNP volunteers and schools with all essential operational supports.
\end{tabular}

exist for the future of nutrition programs. ${ }^{1}$ Surveys were sent to all 14 SNO lead agencies in late April 2020. A total of 16 responses were received $(N=16)$ from 11 regions (response rate $79 \%$ ). Research design, coding of results, and analysis of data were conducted as per Creswell \& Poth (2019).

\section{Results}

\section{Prepandemic}

This section reflects themes that emerged from the data in regards to prepandemic SNP staff work.

Table 2 highlights the major concerns that program staff identified in the ongoing operation of SNPs in prepandemic Ontario.

Our findings indicate that SNP staff operate in an underresourced environment, with staff focused on addressing the gap between funding received and program expenses, as well as the daily operations of program delivery, as discussed below.

\section{Lack of Resources}

The majority of research participants responded that the primary concern in their work was about lack of resources and working to acquire new resources. This finding is in line with evidence from a variety of other research into school nutrition programs that has found them to be chronically underresourced (De Wit, 2012; Russell, Evers, Dwyer, Uetrecht, \& Macaskill, 2008; Winson, 2008). A participant summarized the continual struggle with resources as follows: "Lack of ownership of SNP in one [institutional] home that takes full responsibility (not fully owned by education, public health, community, etc.). Also, universal approach but we don't have the funding to match." Thus, SNPs are expected to serve everyone, but do

Table 2. Prepandemic SNP Concerns

\begin{tabular}{lcl}
\hline Theme & Content Saturation & Details \\
\hline Lack of Resources & $58 \%$ & $\begin{array}{l}\text { Financial, human (volunteers and school staff), physical (food and } \\
\text { kitchen space), growing cost of food, growing demand }\end{array}$ \\
\hline Operational Details & $25 \%$ & Recording deliverables, reporting to funders, training and outreach \\
\hline Managing Relationships & $9 \%$ & $\begin{array}{l}\text { School staff and school boards, volunteers, community partners, } \\
\text { suppliers, funders }\end{array}$ \\
\hline Equity and Safety & $5 \%$ & Unequal fundraising capacities of schools, food safety \\
\hline
\end{tabular}

\footnotetext{
${ }^{1}$ See Appendix for the survey questions.
} 
not receive enough funding to fulfill this mandate. Our data indicate that programs are affected by this funding structure in terms of lack of volunteers, inadequate food budgets, and growing demand in schools. This tension leads to less-than-optimal food environments, where nutritional compromises are made (Holmes, 2019). Furthermore, SNPs operate between the jurisdiction of many different government agencies and initiatives. Consequently, there is lack of ownership of SNPs and associated detriments to programs, such as a patchwork of funding, diffuse governance, and unrealized potential. The fact that nutrition programs are not owned by any one government department in Canada is unique in the global sphere of school nutrition (De Wit, 2012; McLoughlin et al, 2020). Other G7 countries have federally funded nutrition programs that are hosted by their education departments (De Wit, 2012). The inconsistencies between regions and provinces in terms of funding, governance, and approach to SNPs have given rise to long-standing advocacy campaigns for a national school food program in Canada. ${ }^{2}$ Our research suggests that there is substantial potential for school nutrition programs to reduce child food insecurity in Canada through a consistent governance model and appropriate investments.

\section{Operational Details}

The second theme that emerged from the data was the challenges that SNP staff face in accomplishing operational details and administrative tasks, such as recording deliverables and reporting to funders. This finding suggests that nutrition program staff are overleveraged and there are accountability concerns that come with holding responsibility in the patchwork landscape of SNPs described above. Training and outreach were also mentioned as significant concerns for lead agencies, as many of the deliverables (such as tracking program statistics) are completed by volunteers. The additional work SNP staff perform to train volunteers is a result of the community nature of the SNPs (Winson, 2008). In the absence of on-site staff, volunteers deliver the programs and need to capture data accurately for reporting (Pratley, McPhail, \& Webb, 2014).
Volunteerism in SNPs has a high rate of turnover, as children age out of schools, families move, and volunteer capacity fluctuates. Furthermore, some schools see higher rates of volunteer engagement than others based on the age of children, socioeconomic factors, connections with church groups and other organizations, and other factors. Consequently, our data suggest that the heavy reliance on volunteer work that is at the heart of SNPs has significant stresses associated with it.

\section{Managing Relationships}

Managing relationships was mentioned as a large challenge and priority in the work of the lead agencies before COVID-19. In the absence of adequate resources, in-kind donations are essential to the operation of programs and require substantial negotiation and time investment. This is a trend frequently observed in community-based emergency food supply initiatives in Ontario (Tsang, Holt, \& Azevedo, 2011). Interestingly, the stigma associated with participating in school food programs is lowered if there is a lot of community involvement in the program (Edward \& Evers, 2001). Consequently, the value of in-kind donations is greater than material, as social gains are also evident through volunteerism.

Research participants reported that the in-kind resources available to SNPs within schools depend largely on the priorities of key staff and positive relationships between SNP coordinators and staff. As articulated by a participant: "It [the nutrition program] is sometimes a very low priority (despite significant funding). [There are] inconsistent levels of importance and attention depending on the priorities of the individual principals." Schools with principals who are supportive of the SNPs typically have more options for their programs. Consequently, a lot of the work of SNP support staff is contingent on good will; cultivating the social relationships that foster these relationships are part of the support staff's work. The implications of this finding are that in communities or schools where it is not possible to leverage relationships, the quality of the nutrition programs suffer, with a negative impact on child food security.

\footnotetext{
${ }^{2}$ For more information, see Coalition for Healthy School Food and Food Secure Canada
} 


\section{Equity and Safety}

Ensuring equitable and safe administration and delivery of the programs was another concern brought forward by research participants. For example, a few participants mentioned that some schools have larger parent volunteer engagement and a greater ability to fundraise. This leads to differences in their operational budgets and quality of programs. Equity in school food programs is a complex and contested issue both in the field and in the academic literature (De Wit, 2012; Kirkpatrick \& Tarasuk, 2009; Raine, McIntyre, \& Dayle, 2003). We will address this topic briefly in the discussion section of this paper.

In summary, the survey responses paint a clear picture of nutrition programs in Ontario operating within a complex web of relationships with a larger mandate than budget. Our results are aligned with findings in other studies. For instance, De Wit (2012) found a constant funding gap of $67 \%$ in her detailed review of SNPs in Toronto, Ontario. Across Ontario, this funding gap may be larger, as not all programs receive the additional municipal funding that Toronto SNPs do (De Wit, 2012). Our data shows that the budget deficit leads the SNP support staff to continually seek additional resources and manage complex relationships. SNP staff support and manage many different types of responsibilities and relationships, bringing together a diverse network of actors from the government, the charitable sector, community partnerships, industry, and volunteers. Major prepandemic concerns of our research participants were acquiring and managing resources, focusing on operational details, managing relationships, and addressing concerns of equitable program access and quality.
Our findings suggest that prior to the pandemic, SNPs already faced major systemic challenges.

\section{Impact of the Pandemic}

This section reflects themes that emerged from our research data in response to the impact of the pandemic on Ontario SNPs. Table 3 outlines the impact of school closures on nutrition programs and how different regions responded to this challenge.

Survey responses showed far-reaching impacts of school closures with a variety of initiatives that communities created in order to face the pandemic challenges.

\section{Impact of School Closure}

The major impact that the pandemic has had on SNPs is the closure of schools. School closures had far-reaching impacts on the resources available to support possible alternative avenues for providing food to the children who accessed the programs prior to COVID-19. Programs lost access to program space and the children they were serving, as well as other important operational components of the nutrition programs. These include resources within the schools and support staff. One of the research participants described the impact of school closures as follows: "The volunteer base (consisting of parents, teachers, principals etc.) and the meal/snack preparation facilities used by the programs are also valuable resources that have remained unavailable since the closure date." Another research participant indicated that some programs had "difficulty recouping resources that were in the school's possession during school closures." In addition, one lead agency's community development staff members were temporarily laid

Table 3. Impact of COVID-19 on School Nutrition Programs

\begin{tabular}{llll}
\hline Event & Impact & Response & Details \\
\hline School Closures & $\begin{array}{l}\text { Loss of space, access to } \\
\text { children, volunteers, school } \\
\text { resources (physical and } \\
\text { human), staff }\end{array}$ & Changed mandate & $\begin{array}{l}\text { From universal access to targeted food } \\
\text { distribution }\end{array}$ \\
\cline { 3 - 4 } & & $\begin{array}{l}\text { New initiatives and } \\
\text { changed service delivery }\end{array}$ & $\begin{array}{l}\text { New food-security initiatives started by lead } \\
\text { agencies including home delivery, a food } \\
\text { collection warehouse, and grocery vouchers }\end{array}$ \\
\cline { 3 - 4 } & Renegotiated partnerships & $\begin{array}{l}\text { Renegotiation of partnerships with funders, } \\
\text { community organizations, food suppliers, } \\
\text { and volunteers }\end{array}$ \\
\hline
\end{tabular}


off due to COVID-19, drastically reducing the agency's ability to respond to the new circumstances.

\section{Response to School Closures}

Interestingly, many lead agencies were able to create alternative avenues for providing food to children, despite the closure of schools. Our data revealed that responses to the challenges posed by COVID-19 fell into three categories: changed mandate, new initiatives, and partnership renegotiation.

\section{Changed Mandate}

Ten of the 11 regions noted that their mandate shifted from universal access to targeted emergency food supply to vulnerable children and families. One survey participant indicated that, with this shift from universal to focused intervention, there were unexpected benefits: "We are no longer able to provide universal support to all students via schools, so we had more funding to reach children/youth who need it the most." 'This was not the reality for all regions, as many saw an increased strain on the emergency food system due to the COVID-19 lockdown. One participant pointed out that "schools that used to run nutrition programs are now feeding not only students but their families too." Consequently, the financial impact of the pandemic on SNPs was not uniform throughout the province, with some regions seeing focused interventions as creating more room in their budgets and others experiencing the financial strain of supporting whole families.

\section{New Initiatives}

New initiatives were started by seven of the 11 lead agencies that participated in this research. The other four regions shifted their resources to community partnerships (such as food banks) or adapted existing initiatives to the changed circumstances. See Table 4 for an overview. The detailed evaluation of the impact of each of these new initiatives is beyond the scope of this initial COVID-19 impact investigation. Future research would be valuable in understanding in detail the food-security implications of the different lead agency responses.

The new initiatives fell into two categories: financial support to families, and food to families. The decisions of whether to provide food or financial support were based on local logistics circumstances and evaluations of the most efficient use of limited resources. An example of financial support was the establishment of an emergency fund through which families (which had been identified based on household income) received grocery vouchers; one staff member said, "We have reached out to the families of more than 80,000 students who normally access food through SNPs inviting them to register for a grocery card valued at CA $\$ 50$ for each child attending school." Both regions that provided financial support did so through grocery vouchers, which were sent to families in collaboration with school boards and with the help of partner organizations. Grocery vouchers provided accountability and ensured that funding would be spent on food.

The lead agencies that decided to send food directly to families did so in a variety of ways. One involved the creation of food collection warehouses from which families could collect food on a regular basis; according to one staff member, "We developed 3 breakfast hubs for families to pick up breakfast bags containing whole grains, dairy, produce and vouchers that could be redeemed in gro-

Table 4. SNP Response to COVID-19: New Initiatives and Changed Service Delivery

\begin{tabular}{lll}
\hline Response & Type & Details \\
\hline New initiatives $(7)$ & Financial support & Grocery vouchers \\
\hline & Food donation & $\begin{array}{l}\text { Food collection warehouse } \\
\text { - Weekly hampers }\end{array}$ \\
\hline Redirect resources (2) & $\begin{array}{l}\text { Increase capacity of other emergency food supply } \\
\text { to reach children }\end{array}$ & Food banks \\
\hline Expand existing programs (2) & Adjust existing programs to new circumstances & Farm to school \\
\hline
\end{tabular}


cery stores. The three hubs are located in in different areas of the city to ensure that they are accessible to everyone." Two other regions provided weekly hampers that families could either pick up or that were delivered to homes, depending on the circumstances. Other regions worked with partner organizations to make additional food available specifically to the families of children that would usually access the nutrition programs in school. Regions that were not able to create new initiatives as such, or were not able to target families specifically, redirected their resources to other emergency food initiatives in the hopes of reaching the children they served; as one staff members said, "When school initially closed, donations of food and funding were provided to food banks in an effort to support the influx of families with school-aged children."

\section{Partnerships Renegotiated}

Existing partnerships were shifted to meet the increased demands of the pandemic. One research participant noted that "There is a great sense of wanting to work together to help the community. So, old partnerships have been strengthened and new partnerships have been created fairly easily." Ten of the 11 regions emphasized the importance of these partnerships and how they were strengthened through this pandemic. Furthermore, new partnerships were created that did not previously exist: "Agencies are working together that haven't traditionally done so and everyone is working together to do their part more than ever before," noted a research participant. Here again, research participants articulated an unexpected mobilization of resources in light of the pandemic; one said, "We have grown our Farm to School meal program and are working with local farmers (chicken and microgreens) and chefs to prepare meals. We would not have had the capacity and/or funds to do this so quickly in a non-COVID environment."

Given the complex web of relationships that SNPs operated within before the pandemic, it is interesting to see the research data showing how lead agencies leveraged these relationships and were able to respond quickly to the fundamental challenges posed by the COVID-19 pandemic. Though schools were closed on short notice, SNP staff were able to use existing infrastructure and resources to address child hunger in their communities through different avenues. In addition, some regions found that due to the COVID-19 pandemic, they were able to access additional resources and opportunities that had not been available previously. However, the majority of regions continued to be concerned about a lack of resources in meeting the needs of their students. Finally, the shift in focus from universal access programs to targeted food-security intervention for food-insecure households constitutes a fundamental shift in the work SNP staff were accustomed to performing.

In summary, lead agencies responded to the pandemic and associated school closures with targeted emergency hunger relief by leveraging existing relationships to redirect resources to reach children at home. The full impact and efficacy of these new initiatives will need to be scrutinized and evaluated as the pandemic progresses. Traditionally, student nutrition programs are not conceived as solely an emergency food intervention, but an inschool community initiative with a variety of benefits and challenges (De Wit, 2012). The fact that school closures prevent nutrition programs from operating as usual raises fundamental questions about the purpose of the programs in the present and in the future. It also raises questions about the role of nutrition programs in the larger context of food security, child hunger, and sustainable food systems. The fact that there is a lack of ownership over the Ontario nutrition programs and that they are rarely studied systematically (Russel, 2008), exacerbates these questions. Consequently, there is a substantial missed opportunity in addressing child hunger in Ontario through the dedicated investment of resources and leadership and based on robust scholarship.

\section{Future Considerations}

Finally, we asked research participants to address the priorities and concerns that have arisen in their work of supporting SNPs through the pandemic with a view to the future of operating nutrition programs. This question elicited a broad range of responses, with the data clustering around three themes: resources and relationships (39\%), impact 
on vulnerable populations (34\%), and reopening of schools $(27 \%)$.

\section{Resources and Relationships}

The theme of lack of resources, which is central to all aspects of SNPs, was also a major concern for program staff in considering the future of SNPs in the context of COVID-19. Program staff are worried about whether there will be enough funding to support the changed realities that programs face due to COVID-19. SNP support staff anticipate a twofold strain on resources: Firstly, they anticipate increased program participation due to economic hardship and job losses. As expressed by one survey respondent, "We are conscious that the need for SNP will increase dramatically when schools reopen due to the unprecedented job loss resulting from COVID." Secondly, support staff anticipate that with new safety requirements in schools, programs will be more expensive to operate. As stated by one research participant, "We are concerned about having enough funding to continue SNP when student[s] do return to school, since programs will have to operate differently (and will be more costly) than pre-COVID." This concern was echoed throughout other responses from study participants: "I am also concerned about how/when student nutrition programs will start up again and if there may be an even greater lack of funding available. Volunteers will also be hesitant to return so that means programs will likely find it more difficult to run quality programs." From the data, it is evident that the work to gather adequate resources to operate student nutrition programs that was present before the pandemic is now heightened with additional stresses and financial burdens.

\section{Vulnerable Populations}

The second cluster of responses was focused on the impact of COVID-19 on vulnerable children and families. Research participants expressed concerns that new programs created to reach children at home may be inadequate and might not be reaching everyone that needs support. "I'm concerned that families will not ask for help or not know where to access support. ... We are worried that some may be "falling between the cracks,", wrote one SNP support staff member. Survey respondents also addressed the issue of stigma that arose with the changed mandate from universal programs to focused hunger relief: "We hope to have families access these food banks without feeling stigmatized." The data shows that, although program staff are working to find new ways to bring food to vulnerable children, they are unsure about the impact this work is having. This highlights the need for a systematic evaluation of the intentions and impact of the work that SNPs have conducted during COVID-19.

\section{Reopening of Schools}

The third cluster of responses revolved around the theme of schools reopening and associated concerns. SNP support staff are concerned about the uncertainty of the logistics of school-reopening, considering new health restrictions and children staying at home. As one study participant said, "We are very busy preparing for a new reality when students eventually return to school-physical distancing will change the delivery model and likely require new types of food, food preparation, and other additional costs." Furthermore, with some children staying home for distance education, there is the concern that SNPs will need to provide food both in schools and to families at home: "Many students will stay at home, therefore we will have to operate 2 program models in order to continue to reach students."

In considering the future of student nutrition programs, the uncertainty that the pandemic has created is causing program staff to worry about what they have always worried about: lack of resources and capacity. However, this worry is heightened by the severity of the social and economic disruption of COVID-19.

\section{Discussion}

In reviewing the literature on school food in Canada in general, and student nutrition programs in Ontario in particular, it is evident that school food is understood from a variety of perspectives. Nutrition programs are theorized as a place for public health policy, food security intervention, and as an educational site. This disjointed approach to making sense of nutrition programs could be argued to 
be a reflection of the lack of ownership of nutrition programs by any one government department (Russell et al., 2008). Although the Ontario Ministry of Children, Community, and Social Services does seed fund the program (as outlined in the introduction), it does not fully fund the program, and SNPs exist at an intersection of many interest groups (De Wit, 2012). Without coherent program ownership, there are missed opportunities for a cohesive vision and coordinated resources and crisis response. The pandemic raises the question of the purpose of nutrition programs and whether they are relevant beyond an in-person school environment.

In the academic literature, school food and nutrition programs are studied in terms of the development and implementation of nutrition policy (MacLellan, Holland, Taylor, McKenna, \& Hernandez, 2010; MacLellan, Taylor, \& Freeze, 2009;; Taylor et al., 2011; Vine, Harrington, Butler, Patte, Godin, \& Leatherdale, 2017), as a site for public health interventions (McIsaac, Read, Veugelers, \& Kirk, 2017; Pokhrel, Sussman, Black, \& Sun, 2010; Raine, 2005; Vine \& Elliott, 2014b; Winson, 2008), as educational interventions in terms of student performance (Dani, Burrill, \& Demmig-Adams, 2005; Edward \& Evers, 2001; Taras, 2005), as an opportunity for student education in terms of learning about food (Edward \& Evers, 2001), and as a food-security initiative (Kirkpatrick \& Tarasuk, 2009; Ralston et al, 2017; Tarasuk, 2001; Tsang \& Azevedo, 2011). It should also be noted that there is a lack of ongoing, systematic academic research on Ontario SNPs (Russell et al., 2008).

Our research considers nutrition programs primarily from the perspective of food security, thereby contributing to the existing literature on food security and school food (see, for example, Ashe \& Sonnino, 2013; Bartfeld \& Ahn, 2011; Ralston et al., 2017). This interpretive framework was adopted since research participant responses were primarily focused on the food-security implications of COVID-19 on students. Changes made to nutrition programs in response to the pandemic were focused on targeted food-security interventions, as outlined above. There are conflicting opinions in the literature about the value and effi- cacy of school nutrition programs as food-security interventions. On the one hand, Kirkpatrick and Tarasuk (2009) investigate the impact of student nutrition program participation on household food insecurity in Toronto, Ontario. They argue that SNPs do not play a role in decreasing household food insecurity. The evidence presented was (1) low participation rates in SNPs in low-income neighborhoods (one-third of households) and (2) that there was no measurable impact on household food insecurity whether the children attended SNPs or not. It can be argued that the study misses the mark, as SNPs do not aim to improve household food security, but the food insecurity of individual children while at school. Similar results were found by Raine, McIntyre, and Dayle (2003), who argued that SNPs fail to feed the hungriest children due to stigma and the charitable ethos (rather than social justice approach) of SNPs. On the other hand, there are studies that show the positive impact of nutrition programs on the children that participate in them. Ralston et al. (2017) found that participation in nutrition programs increased food security, quality of diet, and contributed to better school performance. Similar results have been shown by Tsang et al. (2011) and Edward and Evers (2001). However, both sides of this debate agree that the fundamental matter at hand is addressing the root cause of food insecurity, namely poverty (; Raine et al., 2003; Tarasuk, 2001; Tsang et al., 2011).

Our research contributes to this debate by highlighting the importance of nutrition programs in providing emergency food to low-income children during a moment of unprecedented challenge. Consequently, we argue that the SNP infrastructure (staff and relationships) strengthens community food security through staff's work, relationships, and resources. At the same time, our research highlights the inadequate and fractured nature of the emergency food supply in Canada. As COVID-19 and its economic impact move more people into economic precarity, this infrastructure will become more relevant and more strained. It is important to remember that Canada's emergency food system was not designed to be permanent (Tsang et al., 2011) and consequently was not designed with the current circumstances in mind. The COVID-19 
pandemic may be our opportunity to construct a permanent food-security, social safety network. For SNPs, this redesign could be an opportunity to build a national student nutrition program in Canada. Evidence from the United States and other G7 countries makes a strong argument for the benefits of a national program. For example, McLoughlin et al. (2020) illustrate how a national school program infrastructure has been able to support communities in the response to COVID-19.

The purpose of this case study is to not to evaluate SNPs as a whole, but merely to understand the impact of the early stages of the COVID19 pandemic on SNPs in Ontario. The data from the surveys we conducted illustrate several interesting findings.

First, the research data of this study illustrate the value of the SNP infrastructure as a community food-security response and shows that there are extensive opportunities to support and strengthen it. Second, our data show that student nutrition programs, while underresourced, are rich in partnerships. These relationships were what enabled SNP support staff to pivot and respond to the pandemic lockdown restrictions quickly and effectively. As a result, SNP support staff were able to bring together different actors in the food system in their communities to move support from the public realm (schools) into the private (homes). The shift from the public to the private is significant, as it changes the fundamental essence of school food initiatives. This presents an unprecedented opportunity to engage with a more holistic approach to eliminating child food insecurity in Ontario, in which the various efforts that exist could be brought into a cohesive initiative. Such an initiative would also present the opportunity for the Canadian government to address its commitment to the UN Sustainable Development Goals, by targeting goal number two, "zero hunger" (Hung, 2016). Addressing the root cause of food insecurity, namely poverty, is an important part of any hunger alleviation work.

Finally, the research data highlight the value of public spaces (such as schools) as venues for stigma-free social support. The COVID-19 pandemic and the initial lockdown forced people in Ontario to retreat into the private and relinquish public spaces. This fact raises many questions and concerns, especially in regard to vulnerable people. Will there be a long-term shift toward distance learning, with children staying at home? If so, what is the place of traditional school feeding programs, such as SNPs, in these circumstances? Will nutrition programs expand their mandate to serve children outside the public realm over the long term? Will children who choose distance education be left out of nutrition support initiatives? How do these altered landscapes interact with stigma-free support, to enable all children who require extra food to receive it? Are SNP interventions effective in reducing child hunger in Ontario? These are some of the questions that the networks of actors that exist to respond to child food insecurity in Ontario will have to grapple with in the months to come. The research data in this study show that SNP support staff are able to adapt to changing circumstances in a crisis situation. The question of long-term sustainability, however, looms large, especially as the course of the pandemic and its impact on schools is very uncertain.

\section{Research Limitations and Opportunities}

Limitations of this research study are that it presents very preliminary findings of an evolving situation. Preliminary findings in rapidly shifting circumstances mean that this research could be quickly outdated. Nevertheless, it presents valuable initial insights and inspiration for future research. Research opportunities that have been amplified through this study include the need for ongoing and systematic study of nutrition programs in Canada (Russell et al., 2008). In particular, the impact of new nutrition program initiatives and the implications of the role and purpose of nutrition programs during school closures require further scrutiny.

\section{Conclusion}

In the early stages of the COVID-19 pandemic, the essence of school food was fractured as schools were closed and children were no longer able to access nutrition programs. This research study shows how the presence of community-embedded student nutrition support staff enabled resources to be redirected to children for targeted emergency 
food response. Through this bounded qualitative case study, we examined the impact of the early stages of the COVID-19 pandemic (March-August 2020) on Student Nutrition Programs in Ontario. Results indicate that program support staff responses to the pandemic fit into three categories: changed mandate, new initiatives, and partnership renegotiation. Changed mandate was the shift from universal access to in-school nutrition programs to targeted food-security initiatives for families. This shift was possible due to the complex web of relationships in which SNPs have always operated.

Funding relationships and community partnerships were present, and staff were able to leverage these to adapt to new circumstances. Considering the far-reaching social and economic impacts of the COVID-19 pandemic, important questions about the structure and purpose of student nutrition programs in Ontario arise. The unprecedented disruption of established food systems by the pandemic presents the opportunity to reconsider, invest in, and restructure school food programs.

\section{Acknowledgments}

Thank you to the peer reviewers for valuable feedback, Stephanie Cran for editing, and to all research participants for their time.

\section{References}

Altieri, M. A., \& Nicholls, C. I. (2020). Agroecology and the reconstruction of a post-COVID-19 agriculture. Journal of Peasant Studies, 47(5), 881-898. https://doi.org/10.1080/03066150.2020.1782891

Anthem, P. (2020, April 16). Risk of hunger pandemic as coronavirus set to almost double acute bunger by end of 2020. World Food Program. Retrieved from https://insight.wfp.org/covid-19-will-almost-double-people-in-acute-hunger-by-end-of-2020-59df0c4a8072

Ashe, L. M., \& Sonnino, R. (2013). At the crossroads: New paradigms of food security, public health nutrition and school food. Public Health Nutrition, 16(6), 1020-1027. https://doi.org/10.1017/S1368980012004326

Bartfeld, J. S., \& Ahn, H. M. (2011). The School Breakfast Program strengthens household food security among lowincome households with elementary school children. The Journal of Nutrition, 141(3), 470-475. https://doi.org/10.3945/jn.110.130823

Chutani, A. M. (2012). School lunch program in India: Background, objectives and components. Asia Pacific Journal of Clinical Nutrition, 21(1), 151-154. https://pubmed.ncbi.nlm.nih.gov/22374572/

Clapp, J. (2020, May 8). Spoiled milk, rotten vegetables and a very broken food system. The New York Times. https://www.nytimes.com/2020/05/08/opinion/coronavirus-global-food-supply.html

Clapp, J., \& G. Moseley, W. (2020). This food crisis is different: COVID-19 and the fragility of the neoliberal food security order. The Journal of Peasant Studies, 47(7), 1393-1417. https://doi.org/10.1080/03066150.2020.1823838

Creswell, J., \& Poth, C. (2019). Qualitative inquiry \& research design: choosing among five approaches (4th ed.). SAGE.

Daily Bread Food Bank (2020). Hunger lives here-Risks and challenges faced by food bank clients during COVID-19. Retrieved from https://www.dailybread.ca/wp-content/uploads/2020/07/DB-COVID-Impact-Report-2020-Final-Web.pdf

Dani, J., Burrill, C., \& Demmig-Adams, B. (2005). The remarkable role of nutrition in learning and behaviour. Nutrition and Food Science, 35(4), 258-263. https://doi.org/10.1108/00346650510605658

Deaton, B. J., \& Deaton, B. J. (2020). Food security and Canada's agricultural system challenged by COVID-19. Canadian Journal of Agricultural Economics/Revue Canadienne D'Agroéconomie, 68(2), 143-149. https://doi.org/10.1111/cjag.12227

De Wit, Y. (2012). Toronto public health: Nourishing young minds. Retrieved from https://www.toronto.ca/wp-content/uploads/2017/11/8f2a-tph-Nourishing-Young-Minds-rep-eng-2012.pdf

Edward, H. G., \& Evers, S. (2001). Benefits and barriers associated with participation in food programs in three lowincome Ontario communities. Canadian Journal of Dietetic Practice and Research, 62(2), 76-81. https://pubmed.ncbi.nlm.nih.gov/11524050/

Florence, M. D., Asbridge, M., \& Veugelers, P. J. (2008). Diet quality and academic Performance. Journal of School Health, 78(4), 209-215. https://doi.org/10.1111/j.1746-1561.2008.00288.x

Food and Agriculture Organization of the United Nations [FAO] (2020, June 9). Emerging data suggest COVID-19 is driving up hunger in vulnerable countries. Retrieved from http:/ /www.fao.org/news/story/en/item/1280414/icode/ 
Food Banks Canada (2020). Food Banks and the COVID-19 crisis-A national snapshot. Mississauga: Food Banks Canada. https://www.foodbankscanada.ca/FoodBanks/MediaLibrary/COVID-Report 2020/A-Snapshot-of-Food-Banksin-Canada-and-the-COVID-19-Crisis EN.pdf

Hailu, G. (2020). Economic thoughts on COVID-19 for Canadian food processors. Canadian Journal of Agricultural Economics/Revue Canadienne D'Agroéconomie, 68(2), 163-169. https://doi.org/10.1111/cjag.12241

Hayes, D., Contento, I. R., \& Weekly, C. (2018). Position of the Academy of Nutrition and Dietetics, Society for Nutrition Education and Behavior, and School Nutrition Association: Comprehensive nutrition programs and services in schools. Journal of the Academy of Nutrition and Dietetics, 118(5), 913-919. https://doi.org/10.1016/j.jand.2018.03.005

Hennebry, J. L., Caxaj, C. S., McLaughlin, J., \& Mayell, S. (2020). Coronavirus: Canada stigmatizes, jeopardizes essential migrant workers. The Conversation. https://theconversation.com/coronavirus-canada-stigmatizes-jeopardizes-essential-migrant-workers-138879

Holmes, S. (2019). The incompatibility of nutrition regulation and market-based internal school food environments in English-Speaking Canada. The International Journal of Sociology of Agriculture and Food, 25(1). https://doi.org/10.48416/ijsaf.v25i1.14

Hung, K. H. (2016). The road to zero hunger: A case study of Canada's policy agenda-setting for global food security. Retrieved from https://ruor.uottawa.ca/handle/10393/34117

King, A., \& Quan, A. (2018). Hunger Report 2018 - A looming crisis: Senior hunger in Ontario. Ontario Association of Food Banks. https://feedontario.ca/wp-content/uploads/2018/11/Hunger-Report-2018-Digital.pdf

Kirkpatrick, S. I., \& Tarasuk, V. (2009). Food insecurity and participation in community food programs among lowincome Toronto families. Canadian Journal of Public Health, 100(2), 135-139. https://doi.org/10.1007/BF03405523

MacLellan, H., Holland, A., Taylor, J., McKenna, M., \& Hernandez, K.(2010). Implementing school nutrition policy: student and parent perspectives. Canadian Journal of Dietetic Practice and Research, 71(4), 172-177. https://doi.org/10.3148/71.4.2010.172

MacLellan, D., Taylor, J., \& Freeze, C. (2009). Developing school nutrition policies: Enabling and barrier factors. Canadian Journal of Dietetic Practice and Research, 70(4), 166-171. https://doi.org/10.3148/70.4.2009.166

McIntyre, L., \& Dayle, J. B. (1992). Exploratory analysis of children's nutrition programs in Canada. Social Science \& Medicine, 35(9), 1123-1129. https://doi.org/10.1016/0277-9536(92)90224-E

McIsaac, J. L. D., Read, K., Veugelers, P. J., \& Kirk, S. F. (2017). Culture matters: A case of school health promotion in Canada. Health Promotion International, 32(2), 207-217. https://doi.org/10.1093/heapro/dat055

McLoughlin, G. M., Turner, L., Leider, J., Piekarz-Porter, E., \& Chriqui, J. F. (2020). Assessing the relationship between district and state policies and school nutrition promotion-related practices in the United States. Nutrients, 12(8), 2356. https://doi.org/10.3390/ nu12082356

Ministry of Children, Community, and Social Services. (2016). Student Nutrition Program guidelines. Retrieved from https://www.ontario.ca/document/student-nutrition-program-guidelines-2016/section-1-purpose-nutritionguidelines

Paslakis, G., Dimitropoulos, G., \& Katzman, D. K. (2021). A call to action to address COVID-19-induced global food insecurity to prevent hunger, malnutrition, and eating pathology. Nutrition Reviews, 79(1), 114-116. https://doi.org/10.1093/nutrit/nuaa069

Pokhrel, P., Sussman, S., Black, D., \& Sun, P. (2010). Peer group self-identification as a predictor of relational and physical aggression among high school students. Journal of School Health, 80(5), 249-258. https://doi.org/10.1111/j.1746-1561.2010.00498.x

Pratley, E., McPhail C., \& Webb, C. (2014). Innovative student nutrition programs in Ontario: Identifying case study examples. Guelph, ON: Institute for Community Engaged Scholarship. https://atrium.lib.uoguelph.ca/xmlui/bitstream/handle/10214/9055/StudentNutritionPrograms.pdf

Raine, K. D. (2005). Determinants of healthy eating in Canada: An overview and synthesis. Canadian Journal of Public Health/Revue Canadienne De Sante'e Publique, 96, S8-S14. https://doi.org/10.1007/BF03405195 
Raine, K., McIntyre, L., \& Dayle, J. B. (2003). The failure of charitable school-and community-based nutrition programmes to feed hungry children. Critical Public Health, 13(2), 155-169. https://doi.org/10.1080/0958159031000097634

Ralston, K., Treen, K., Coleman-Jensen, A., \& Guthrie, J. (2017). Children's food security and USD A child nutrition programs (No. 1476-2017-2076). U.S. Department of Agriculture, Economic Research Service (USDA ERS). Retrieved from https://www.ers.usda.gov/publications/pub-details $/$ ?pubid $=84002$

Russell, E., Evers, S., Dwyer, J. M., Uetrecht, C. \& Macaskill, L. (2008). Best practices among child nutrition programs in Ontario: Evaluation findings. Journal of Hunger \& Environmental Nutrition, 2(2-3), 111-127. https://doi.org/10.1080/19320240801891511

Student Nutrition Ontario [SNO]. (n.d.). About. Retrieved September 2020 from https://studentnutritionontario.ca/about/

Taras, H. (2005). Nutrition and student performance at school. Journal of School Health, 75(6), 199-213. https://doi.org/10.1111/j.1746-1561.2005.00025.x

Tarasuk, V. (2001). A critical examination of community-based responses to household food insecurity in Canada. Health Education \& Behavior, 28(4), 487-499. https://doi.org/10.1177/109019810102800408

Taylor, J. P., MacLellan, D., Caiger, J. M., Hernandez, K., McKenna, M., Gray, B., \& Veugelers, P. (2011). Implementing elementary school nutrition policy: Principals' perspectives. Canadian Journal of Dietetic Practice and Research, 72(4), e205-e211. https://doi.org/10.3148/72.4.2011.e205

Tsang, S., Holt, A. M., \& Azevedo, E. (2011). An assessment of the barriers to accessing food among food-insecure people in Cobourg, Ontario. Chronic Diseases and Injuries in Canada, 31(3), 121-128. https://doi.org/10.24095/hpcdp.31.3.06

Vine, M. M., \& Elliott, S. J. (2014a). Examining local-level factors shaping school nutrition policy implementation in Ontario, Canada. Public Health Nutrition, 17(6), 1290-1298. https://doi.org/10.1017/S1368980013002516

Vine, M. M., \& Elliott, S. J. (2014b). Exploring the school nutrition policy environment in Canada using the ANGELO framework. Health Promotion Practice, 15(3), 331-339. https://doi.org/10.1177/1524839913498087

Vine, M. M., Elliott, S. J., \& Raine, K. D. (2014). Exploring implementation of the Ontario school food and beverage policy at the secondary-school level: A qualitative study. Canadian Journal of Dietetic Practice and Research, 75(3), 118124. https://doi.org/10.3148/cjdpr-2014-003

Vine, M. M., Harrington, D. W., Butler, A., Patte, K., Godin, K., \& Leatherdale, S. T. (2017). Compliance with school nutrition policies in Ontario and Alberta: An assessment of secondary school vending machine data from the COMPASS study. Canadian Journal of Public Health, 108(1), e43-e48. https://doi.org/10.17269/CJPH.108.5701

Winson, A. (2008). School food environments and the obesity issue: Content, structural determinants, and agency in Canadian high schools. Agriculture and Human V alues, 25(4), 499-511. https://doi.org/10.1007/s10460-008-9139-8

Yaffe-Bellany, D., \& Corkery, M. (2020a, April 11). Dumped milk, smashed eggs, plowed vegetables: Food waste of the pandemic. The New York Times. https://www.nytimes.com/2020/04/11/business/coronavirus-destroying-food.html

Yaffe-Bellany, D., \& Corkery, M. (2020b, May 14). Meat plant closures mean pigs are gassed or shot instead. The New York Times. https://www.nytimes.com/2020/05/14/business/coronavirus-farmers-killing-pigs.html 


\section{Appendix. Survey Questions}

1. Before the beginning of the COVID-19 pandemic, what were the major challenges that the student nutrition program in your region faced?

2. Before the beginning of the COVID-19 pandemic, what was the major focus of your work in supporting nutrition programs?

3. How are programs in your region affected by COVID-19?

4. What is the main focus of your work in supporting nutrition programs in dealing with COVID-19? What are you most concerned about?

5. How have nutrition programs in your region changed since the start of the pandemic? What new initiatives have started to meet the nutrition needs of children with COVID-19 restrictions in place?

6. Have your community partnership relationships been affected by COVID-19? If so, how? 